\title{
Carbon Materials Reinforced Aluminum Composites: A Review
}

\author{
Yu Huang $\cdot$ Qiubao Ouyang $\cdot$ Di Zhang $\cdot$ Jing Zhu $\cdot$ Ruixiang Li $\cdot$ Hong Yu
}

Received: 14 May 2014/Revised: 16 September 2014/Published online: 16 October 2014

(C) The Chinese Society for Metals and Springer-Verlag Berlin Heidelberg 2014

\begin{abstract}
Carbon materials, including carbon fibers, graphite, diamond, carbon foams, carbon nanotubes, and graphene, are attractive reinforcements for aluminum matrix composites due to their excellent mechanical and/or physical properties as well as light weight. Carbon materials reinforced aluminum (C/Al) composites are promising materials in many areas such as aerospace, thermal management, and automobile. However, there are still some challenging problems that need to be resolved, such as interfacial reactions, low wettability, and anisotropic properties. These problems have limited the use of these composites. This review mainly focuses on the categories, fabrication processes, existing problems and solutions, coatings and interfaces, challenges and opportunities of $\mathrm{C} / \mathrm{Al}$ composites so as to provide a useful reference for future research.
\end{abstract}

\section{KEY WORDS: Carbon materials; Aluminum composites; Fabrication; Interface; Coatings}

\section{Introduction}

Carbon materials reinforced aluminum $(\mathrm{C} / \mathrm{Al})$ composites, including carbon fibers, graphite, diamond, carbon foams, carbon nanotubes (CNTs), and graphene reinforced aluminum composites, are attracting significant interest because of their light weight, superior mechanical properties and/or thermal conductivity (TC), and low coefficient of thermal expansion (CTE) [1-9]. Due to these benefits, C/Al composites have become promising materials for

Available online at http://link.springer.com/journal/40195

Y. Huang $\cdot$ Q. Ouyang $(\bowtie) \cdot D$. Zhang

State Key Laboratory of Metal Matrix Composites, Shanghai

Jiao Tong University, Shanghai 200240, China

e-mail: oyqb@sjtu.edu.cn

\section{J. Zhu}

Shanghai Composites Science and Technique Co., Ltd, Shanghai 201112, China

R. Li · H. Yu

Shanghai Key Laboratory of Spacecraft Mechanism, Shanghai 201108, China applications in areas such as aerospace, thermal management, and automobile [1, 2, 4, 7-11]. Actually, C/Al composites have already found applications in some occasions of the above areas. For example, carbon fibers/Al composites have been used in Hubble Space Telescope antenna waveguide mast [2]. Short carbon fibers/Al composites and graphite platelets/Al composites with high TC and controlled CTE have been produced for thermal management [11]. Diamond/Al composites with high TC produced by Nano Materials International Corporation have already been used in thermal management [12].

However, C/Al composites still have some problems that need to be solved, which retard wider application of these composites. The main issues include [1, 6, 8, 13-21]: (1) Wettability between aluminum and carbon materials is poor; (2) At high temperature, carbon materials will react with aluminum to form a brittle aluminum carbide $\mathrm{Al}_{4} \mathrm{C}_{3}$, which strongly decreases the properties of the composites; (3) The properties of some kinds of carbon materials are anisotropic, which means their excellent properties are along one or two directions while the properties in the other directions are poor.

With decades of research, the following methodologies have been proposed in order to address the above 
problems: (1) Optimizing the fabrication parameters such as applying an appropriate pressure to promote infiltration, limiting the high temperature contact time or using low temperature fabrication methods such as powder metallurgy [19, 22-24]. These methods are widely accepted, however, to be not enough to solve the problem of interfacial reactions. (2) Adding alloy elements such as $\mathrm{Mg}$ or Si to improve the wettability $[16,25,26]$. This method is effective but the matrix composition is modified, which may affect the overall properties of the composites. (3) Coating the carbon materials to produce diffusional barriers to prevent interfacial reactions and/or improve wettability, such as Ni [24, 27-35], $\mathrm{Cu}$ [27-29, 36-39], W [40], Ti [41-43], SiC [44-48], TiC [44, 46, 49-53], $\mathrm{Al}_{2} \mathrm{O}_{3}$ [54, 55], $\mathrm{TiO}_{2}[29,56], \mathrm{ZrO}_{2}[57,58]$ and pyrolytic carbon [44, $59,60]$ coatings. This method is effective and widely accepted, and it will be discussed in detail later. (4) Controlling the orientation of the anisotropic reinforcements to get high properties along one or two directions [4, 8].

The intent of this review is to describe the current states, challenges and opportunities of $\mathrm{C} / \mathrm{Al}$ composites so as to provide a reference for researchers. The categories of carbon materials and $\mathrm{C} / \mathrm{Al}$ composites, fabrication processes, coatings, interfacial structures and prospects of $\mathrm{C} / \mathrm{Al}$ composites will be discussed in detail, respectively.

\section{Carbon Materials}

Due to different allotropes (graphite, diamond, fullerenes/ nanotubes), various microtextures (more or less ordered) owing to the degree of graphitization, a rich variety of dimensionality from 0 to $3 \mathrm{D}$ and the ability for existence under different forms (from powders to fibers, flakes, fabrics and foams) [61], carbon materials contain many members with superior properties, which makes them to be appealing reinforcements for composites.

Table 1 shows the mechanical and physical properties of a few carbon materials. Polyacrylonitrile (PAN)-based carbon fibers are carbon fibers fabricated from PAN precursors $[61,62]$. According to the degree of graphitization, PAN-based carbon fibers can be classified into carbon fibers such as T300 and T700 and graphite fibers such as M40 and M60. High-performance Pitch-based carbon fibers are usually based on mesophase pitch precursors [61, 62]. These carbon fibers are more easily graphitized and have much higher TC compared to PAN-based carbon fibers [61]. Vapor grown carbon fibers (VGCFs) are carbon fibers fabricated by vapor grown process, and the diameters of these fibers range from nanometer to micrometer [64, 65]. These carbon fibers are of great interest due to their excellent properties and higher cost performance for mass production than CNTs [65].

CNTs and graphene are well-known carbon materials; however, the dispersion, direction and interface controlling of these carbon materials are difficult tasks which attract many attentions [6-8]. Graphite and diamond are ideal reinforcements in metal matrix composites for thermal management. It is worth noting that due to the defects and impurities, the properties of these carbon materials may vary extensively [61]. Carbon foams are ideal thermal management materials with open-celled structure, low density, relatively high surface area and high TC [68].

Generally, carbon materials with high degree of graphitization are less reactive with aluminum matrix [1]. Among all kinds of carbon materials, graphite and diamond are relatively less reactive with aluminum compared to carbon fibers, CNTs and graphene. Specially, the

Table 1 Properties of carbon materials

\begin{tabular}{|c|c|c|c|c|c|c|}
\hline Materials & Density $\left(\mathrm{g} / \mathrm{cm}^{3}\right)$ & Strength (GPa) & Modulus (GPa) & $\mathrm{TC}\left(\mathrm{W} \mathrm{m} \mathrm{m}^{-1} \mathrm{~K}^{-1}\right)$ & CTE $\left(10^{-6} \mathrm{~K}^{-1}\right)$ & Ref. \\
\hline PAN-based carbon fibers & $1.75-1.93$ & $2.5-7.0$ & $250-400$ & $8-70$ & $(-0.6)-(-1.1)$ & {$[1,61-63]$} \\
\hline Pitch-based carbon fibers & $2.10-2.19$ & $1.5-3.5$ & $200-800$ & $530-1,100$ & $(-1.3)-(-1.45)$ & {$[1,61-63]$} \\
\hline VGCFs & 2.0 & $2.35-2.9$ & $180-245$ & 1,950 & $1-4$ & {$[8,64,65]$} \\
\hline Crystalline graphite & 2.3 & - & - & $\begin{array}{l}x-y: 3,000 \\
z: 6\end{array}$ & $\begin{array}{l}x-y:-1.0 \\
z: 29\end{array}$ & {$[66]$} \\
\hline Graphite flakes & $2.1-2.3$ & - & - & a & $\mathrm{a}$ & {$[66]$} \\
\hline Graphite particles & $2.1-2.3$ & - & - & $\mathrm{b}$ & $\mathrm{b}$ & {$[66]$} \\
\hline Carbon foams & 0.9 & - & - & $\begin{array}{l}x-y: 70 \\
z: 245\end{array}$ & $\begin{array}{l}x-y: 1.02 \\
z:-1.07\end{array}$ & {$[66]$} \\
\hline Diamond & 3.51 & - & - & $2,000-2,200$ & 1.3 & {$[66]$} \\
\hline CNTs & 2.1 & $11-150$ & $270-950$ & $500-3,500$ & $(-10)-(-12)$ & {$[7,8,67]$} \\
\hline Graphene & - & 130 & 1,002 & $4,840-5,300$ & -1.3 & {$[8,67]$} \\
\hline
\end{tabular}

${ }^{a}$ Although thermal properties could be similar to those of crystalline graphite, defects and impurities may considerably reduce them

b Spheroidized purified natural graphite; again defects and impurities may considerably reduce their thermal properties 
orientations of the graphite planes in carbon fibers have a great effect on the reactivity of the fibers due to the fact that a graphite plane is chemically active only on the edge of the plane, where dangling bonds are present [58]. Figure 1 shows the orientations of the graphite planes of several common kinds of carbon fibers, the reactivity of the fibers decreases from Fig. 1a-c.

\section{Categories of C/Al Composites}

Each carbon material mentioned above can be fine reinforcement for aluminum matrix composites. This part will briefly introduce the categories of $\mathrm{C} / \mathrm{Al}$ composites.

\subsection{Carbon Fibers/Al}

According to categories of the carbon fibers, carbon fibers/ Al composites can be classified into PAN-based carbon fibers/Al composites, pitch-based carbon fibers/Al composites, VGCFs/Al composites, and so on.

According to morphologies of the reinforcements or composites, carbon fibers/Al composites can be classified into continuous fiber composites, short fiber composites, carbon nanofiber composites, and laminate composites. Here laminate composites are hybrid composites based on thin sheets of metal alloys and plies of fiber reinforced polymers, as shown in Fig. 2 [69, 70].

\subsection{Graphite/Al}

According to morphologies of the graphite, graphite/Al composites can be classified into graphite particles/Al composites and graphite platelets/Al composites. Graphite is introduced into aluminum for thermal management consideration because it has low density and can increase the TC meanwhile decrease the CTE of the aluminum matrix.

\subsection{Diamond/Al}

Diamond/Al composites are ideal materials for applications in heat sink and electronic packaging due to the combination of high TC and tailorable CTE, as well as the low density [71, 72]. However, an obvious drawback of diamond/Al composites is their poor machinability [66], which strongly limits the use of these materials.

\subsection{Carbon Foams/Al}

Report about carbon foams/Al composites is rarely found perhaps due to the fact that carbon foams can be directly used for thermal management $[68,73,74]$. However, according to Prieton et al. [66] on the properties of carbon foams/Al composites, we believe that these composites can be used in some special occasions that require good TC in all directions.

\subsection{CNTs/Al and Graphene/Al}

Recently, CNTs and Graphene have drawn many attentions for their excellent mechanical and physical properties [68]. Bakshi et al. [6] and Tjong [8] have already reviewed the research works carried out in the field of CNTs and Graphene reinforced metal matrix composites. Accordingly, this review will mainly focus on the other kinds of carbon materials, but it is worth noting that many scientific

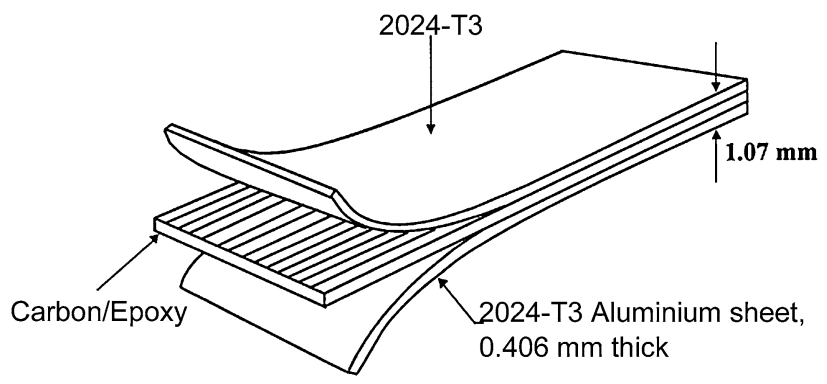

Fig. 2 Schematic illustration of a 2/1 carbon fibers/Al laminate [69]
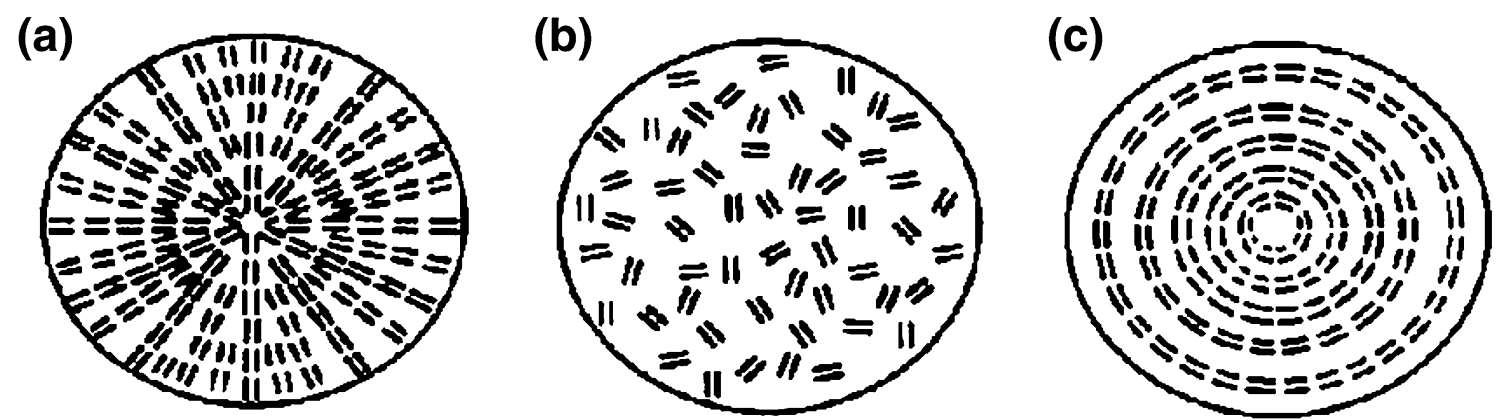

Fig. 1 Common orientations of graphite planes in fibers [58]: a radial; $\mathbf{b}$ random; $\mathbf{c}$ onion skin 
problems, such as fabrication processes, wetting problem, interfacial reactions, coatings, and so on, are similar in all kinds of $\mathrm{C} / \mathrm{Al}$ composites.

In summary, $\mathrm{C} / \mathrm{Al}$ composites contain many members that can be used in both structural and functional applications. The properties of these materials can be targeteddeveloped with the selection of carbon materials and aluminum matrix, architecture design of the composites and so on to meet the requirements of the applications.

\section{Fabrication of C/Al Composites}

To fabricate C/Al composites with good and stable mechanical and/or thermal properties is a challenging task. There are many problems, such as interfacial reactions and poor wettability, for researchers to conquer.

Chemical reactions between carbon materials and aluminum matrix can occur readily at the fabrication conditions, which will cause the formation of $\mathrm{Al}_{4} \mathrm{C}_{3}$ (Fig. 3) [15, 17, 18]:

$4 \mathrm{Al}+3 \mathrm{C} \rightarrow \mathrm{Al}_{4} \mathrm{C}_{3}$.

$\mathrm{Al}_{4} \mathrm{C}_{3}$ is a brittle phase which is adverse to both mechanical and physical properties of the composites. Thus, the interfacial reactions must be controlled during fabrication of $\mathrm{C} / \mathrm{Al}$ composites.

The wetting of carbon material surface with molten aluminum plays an important role in the composite fabrication. For a liquid droplet on a solid surface (Fig. 4a [8]), the surface energy (tension) of different components can be expressed by [8]:

$\gamma_{\mathrm{SV}}=\gamma_{\mathrm{SL}}+\gamma_{\mathrm{LV}} \cos \phi$,

where $\phi$ is the contact angle, $\gamma_{\mathrm{SV}}, \gamma_{\mathrm{SL}}$ and $\gamma_{\mathrm{LV}}$ are the surface tensions of solid-vapor, solid-liquid, and liquid-vapor, respectively. At $\phi<90^{\circ}$, the liquid droplet wets the solid. The liquid does not wet solid for $\phi>90^{\circ}$. In general, carbon materials have poor wettability by aluminum. The contact angle ranges from $140^{\circ}$ to $160^{\circ}$ as shown in Fig. $4 \mathrm{~b}, \mathrm{c}[8,13,58,75]$.

The main techniques currently employed for fabrication of $\mathrm{C} / \mathrm{Al}$ composites include liquid metallurgy processing and powder metallurgy processing. Each of the main processing routes can be further classified into several different categories. For example, liquid metallurgy processing includes stir casting, gas pressure infiltration, squeeze casting, and ultrasonic infiltration. Powder metallurgy route includes vacuum hot pressing and spark plasma sintering.

This part will discuss these fabrication methods in detail and the efforts made by researchers to solve the fabrication problems mentioned above by controlling the fabrication parameters.

\subsection{Liquid Metallurgy Processing}

\subsubsection{Stir Casting}

The process of stir casting generally involves the admixture of reinforcements with a molten metal matrix by mechanical stirring (Fig. 5) [2, 8], and it is usually used in ceramic particles reinforced aluminum composites. For $\mathrm{C} / \mathrm{Al}$ composites, this process is rarely used due to low density and easy agglomeration of carbon materials as well as poor wettability between carbon materials and $\mathrm{Al}$. However, there are still some researchers trying to fabricate short carbon fibers/Al composites by stir casting. Naji et al. [76] used stir casting to fabricate short carbon fibers/Al composites to study the effect of volume fraction and aspect ratio of carbon fibers on fracture toughness of the composites. Bhav et al. [38] used copper-coated short carbon fibers to fabricate aluminum composites by stir casting and get a strength improvement of $40 \%$ by adding 4 wt\% carbon fibers.

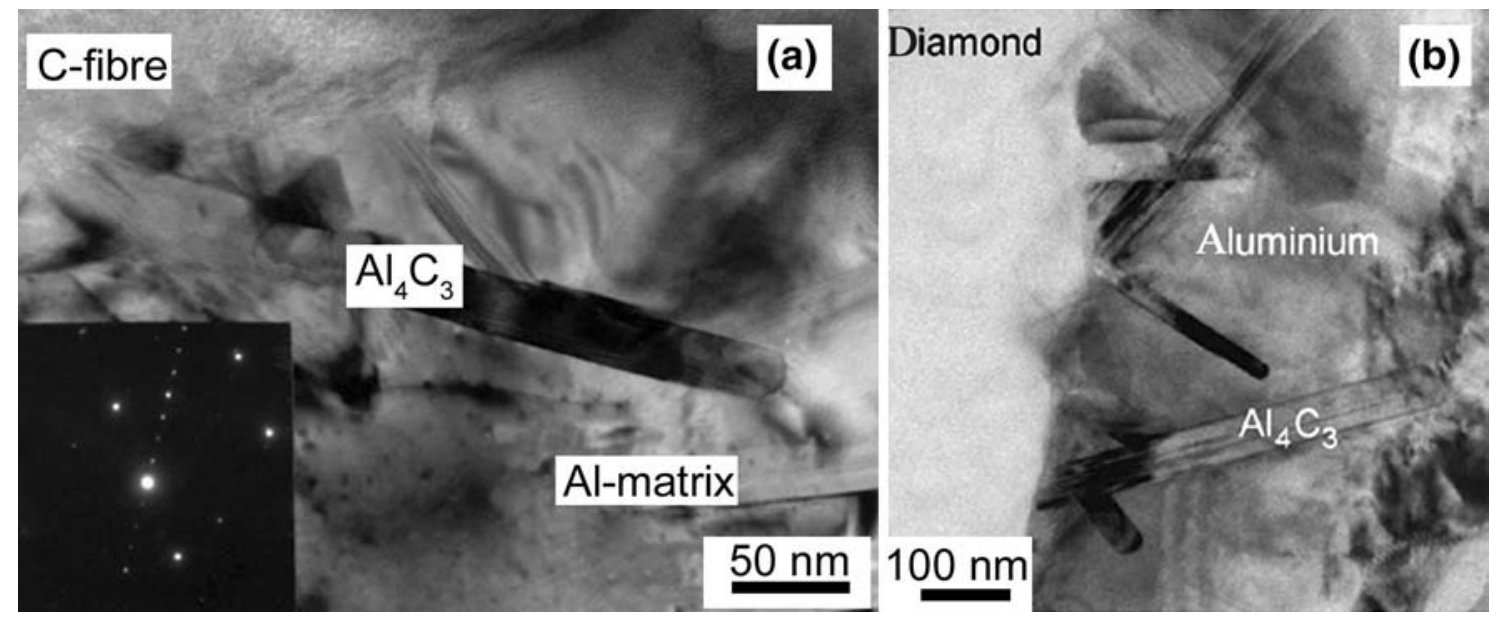

Fig. 3 Formation of $\mathrm{Al}_{4} \mathrm{C}_{3}$ in some typical $\mathrm{C} / \mathrm{Al}$ composites [15, 90]: a Carbon fibers/Al composites; b Diamond/Al composites 

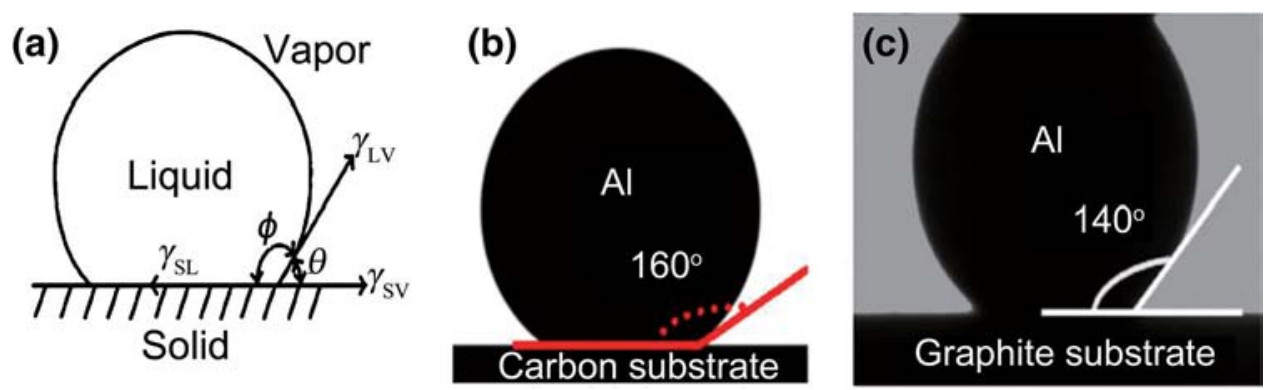

Fig. 4 Contact angle between carbon materials and aluminum [8, 58]: a schematic diagram; $\mathbf{b}$ carbon substrate; $\mathbf{c}$ graphite substrate

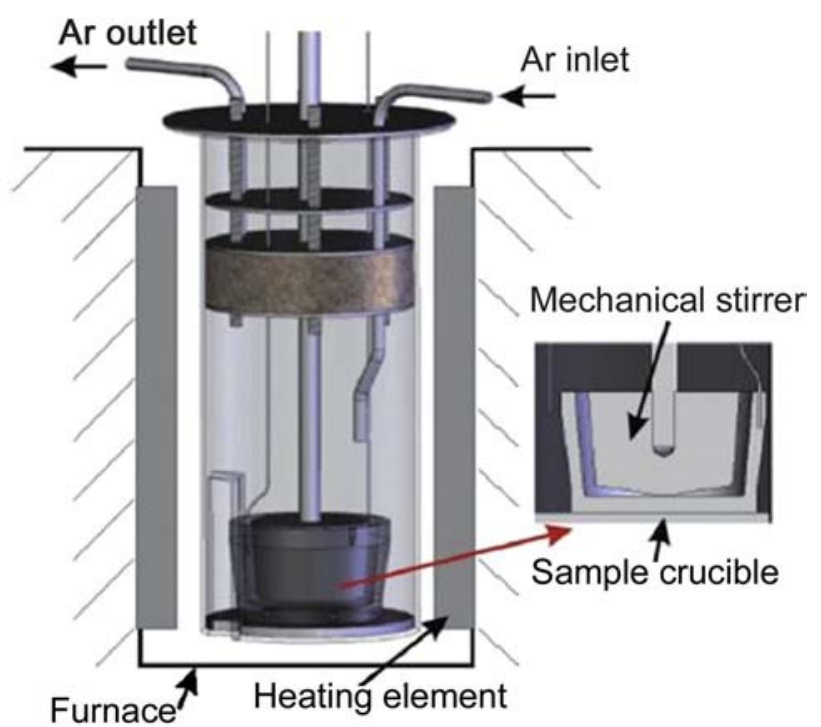

Fig. 5 Schematic diagram of stir casting [8]

In summary, this process is low cost and can be used for mass production; however, it is not a smart choice for C/Al composites compared to other fabrication processes [2].

\subsubsection{Gas Pressure Infiltration}

Gas pressure infiltration is a process that uses gas pressure to drive the molten aluminum into a preform which is held in vacuum condition (Fig. $6[60,77])$. This method was widely used to fabricate aluminum matrix composites [2]. It can be used to fabricate many kinds of C/Al composites, such as continuous [23, 78-83] or short [37, 60, 84, 85] carbon fibers/Al composites, VGCFs/Al composites [64, 86], graphite/Al composites [66, 87-89], diamond/Al composites [90, 91, 92], etc.

Preform is very important for gas pressure infiltration. To obtain an effective reinforcement, the preform must meet the following requirements [93, 94]: extreme cleanliness, homogeneous reinforcement distribution, homogeneous binder distribution, low binder content, and sufficient preform strength.

Gas pressure is used to solve the wetting problem between carbon materials and molten aluminum. However, at the high temperature of infiltration, violent interfacial reactions will occur. Two methods have been proposed to address this problem: coating the carbon materials which will be discussed later and optimizing the fabrication parameters such as temperature and high temperature contact time.

Jacquesson et al. [80] used gas pressure infiltration to fabricate K139 carbon fibers reinforced A357 aluminum alloys $\left(V_{\mathrm{f}}=58 \%\right)$ with tensile strength and modulus of 1,083 $\mathrm{MPa}$ and $395 \mathrm{GPa}$, respectively, but the fabrication parameters are not given. However, it was also found that carbon fibers/Al composites fabricated by this process exhibited relatively poor properties [78, 81, 82], which

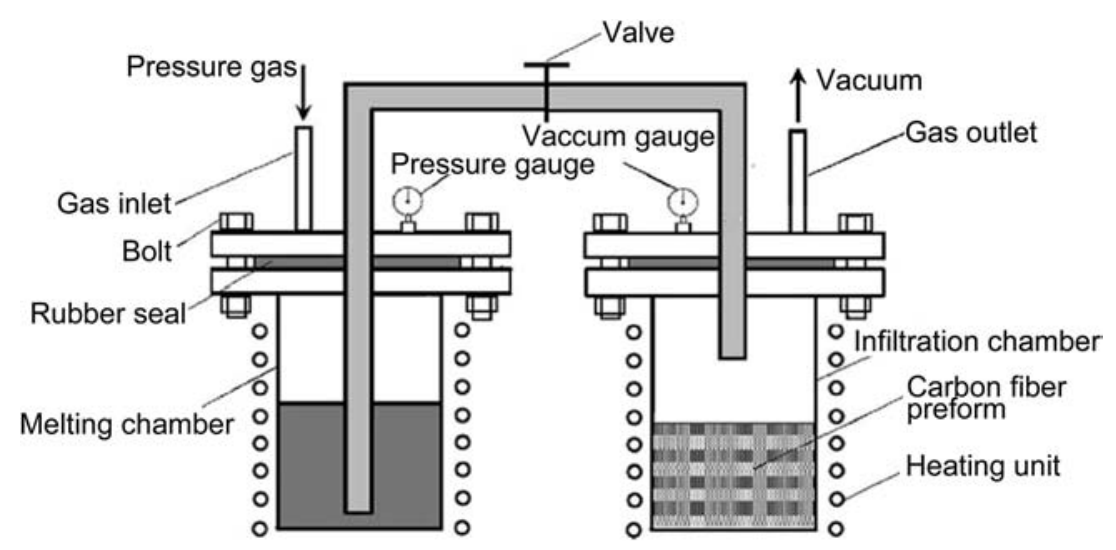

Fig. 6 Schematic diagram of gas pressure infiltration [60] 
indicate that it is a difficult task to fabricate carbon fibers/ $\mathrm{Al}$ composites by optimizing the fabrication parameters.

For diamond/Al composite, Monje et al. [95] obtained composites with TC up to $670 \mathrm{~W} \mathrm{~m}^{-1} \mathrm{~K}^{-1}$ by optimizing the fabrication parameters of gas pressure infiltration. Chang et al. [89] fabricated graphite/Al composites with TC of $500-600 \mathrm{~W} \mathrm{~m}^{-1} \mathrm{~K}^{-1}$ by optimizing the fabrication parameters.

Thus, for carbon materials with low reactivity with the matrix, such as diamond and graphite, it may be an effective way to partially solve the problem of interfacial reactions by optimizing the fabrication parameters of gas pressure infiltration. However, for high reactive carbon materials, such as carbon fibers, optimizing the fabrication parameters may be not enough to obtain $\mathrm{C} / \mathrm{Al}$ composites with good properties. As a result, coatings of carbon materials should be introduced.

\subsubsection{Squeeze Casting}

Squeeze casting is different from gas pressure infiltration because it uses mechanical pressure, rather than gas pressure to push the molten aluminum into carbon material preforms (Fig. 7 [37]). The mechanical pressure is usually higher than the gas pressure (about 100 vs. 2-20 MPa) [77]. Similar to gas pressure infiltration, squeeze casting can be used to fabricate many kinds of $\mathrm{C} / \mathrm{Al}$ composites, such as continuous [24, 96-98] or short [37, 99-101] carbon fibers/Al composites, graphite/Al composites [102], etc.

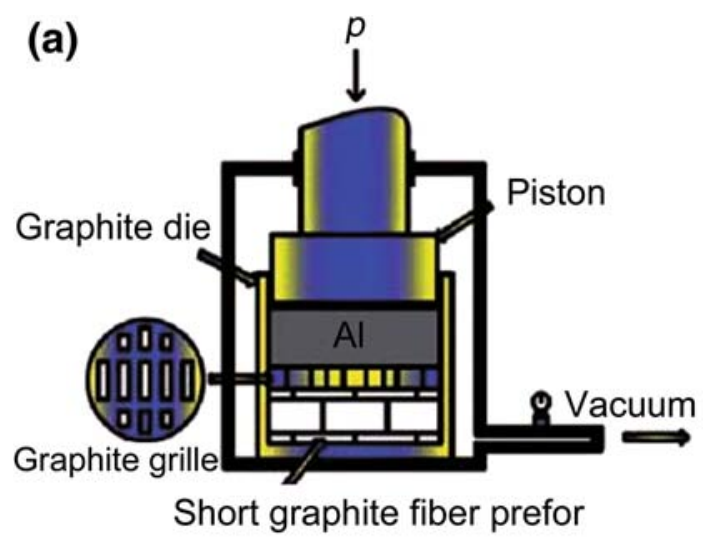

(b)

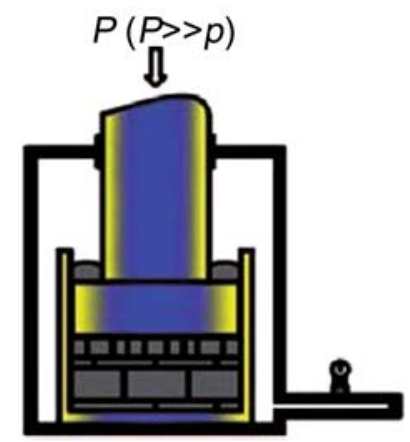

Fig. 7 Schematic diagram of squeeze casting [37]
A high quality preform is needed for squeeze casting process just like the gas pressure infiltration process. Interfacial reaction is the biggest problem for squeeze casting process. Many researchers try to fabricate uncoated carbon fibers/Al composites by squeeze casting process through optimizing process parameters [96, 97, 103]. However, only Towata et al. [103] obtained composites with tensile strength of 1.29-1.41 GPa and modulus of 266-280 GPa by using uncoated PAN-based carbon fibers with 'onion' type orientation of graphite basal planes (as shown in Fig. 1c) which are relatively less reactive with aluminum matrix.

\subsubsection{Ultrasonic Infiltration}

Ultrasonic infiltration process is usually used to fabricate continuous carbon fibers/Al composite wires. The fabrication apparatus and microstructure of composites are shown in Fig. 8 [104, 105]. Tensile strength and modulus of the composite wires can reach $1.6 \mathrm{GPa}$ and $210 \mathrm{GPa}[105$, 106], respectively, which are sensitive to strain rate [106].

In summary, among all kinds of liquid metallurgy processes, only gas pressure infiltration and squeeze casting are almost suitable for all kinds of $\mathrm{C} / \mathrm{Al}$ composites. High quality preforms and controlling of high temperature interfacial reactions are the core issues of these processes.

\subsection{Powder Metallurgy Processing}

In order to reduce interfacial reactions, a relatively low temperature fabrication process called powder metallurgy process is used. Powder metallurgy processing method can be used to fabricate many kinds of $\mathrm{C} / \mathrm{Al}$ composites, such as VGCFs/Al composites [65, 107-109], short carbon fibers/Al composites [110], diamond/Al composites [71, 72, 111-114], graphite/Al composites [115], CNTs/Al composites and graphene/Al composites [7, 8]. This process involves mechanical blending of carbon material

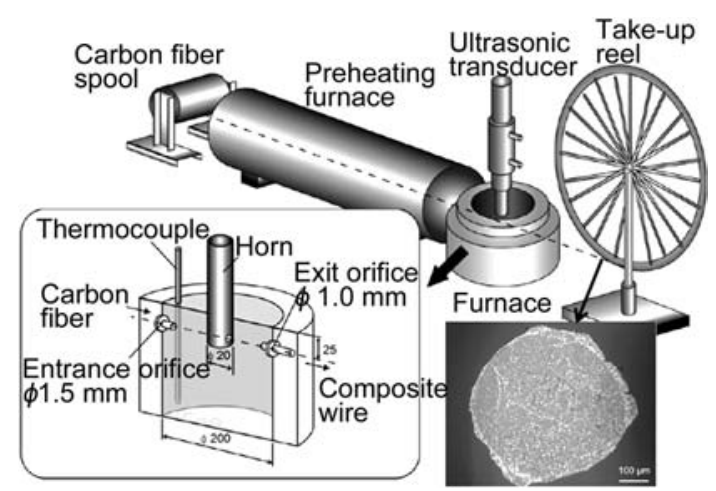

Fig. 8 Fabrication apparatus and microstructure of continuous carbon fibers/Al composites wires [104, 105] 
reinforcements with aluminum powders in a rotary mill, followed by compaction and sintering [8]. According to the methods used to sinter the composites, they can be divided into two categories, namely spark plasma sintering and vacuum hot pressing.

\subsubsection{Spark Plasma Sintering}

Figure 9 shows the schematic diagram of spark plasma sintering. Due to the high efficiency (usually with holding time as short as several minutes) and rather low temperatures (only 520-600 ${ }^{\circ} \mathrm{C}$ ) of this process [71], it is widely used to fabricate $\mathrm{C} / \mathrm{Al}$ composites. Xu et al. [65, 108, 109] systematically studied the fabrication process, mechanical properties, thermal properties, electrical properties and microstructures of $\mathrm{VGCFs} / \mathrm{Al}$ composites fabricated by spark plasma sintering. Ke et al. systematically studied the effect of powder mixing process [111], sintering temperature [113] and particle size [112] on the microstructure and $\mathrm{TC}$ of diamond/Al composites fabricated by spark plasma sintering. However, the interfacial bonding of diamond/Al composites fabricated by common spark plasma sintering is not favorable, thus causing low TC [71]. Mizuuchi et al. [114] used a continuous solid-liquid co-existent state spark plasma sintering to fabricate diamond/Al composites with TC of $552 \mathrm{~W} \mathrm{~m}^{-1} \mathrm{~K}^{-1}$, which is much higher than $325 \mathrm{~W} \mathrm{~m}^{-1} \mathrm{~K}^{-1}$ of common spark plasma sintering diamond/Al composites [112].

\subsubsection{Vacuum Hot Pressing}

In order to improve the interfacial bonding of diamond/Al composites, Tan et al. [71, 72] proposed a vacuum hot pressing method to fabricate diamond/Al composites with high TC of $496 \mathrm{~W} \mathrm{~m}^{-1} \mathrm{~K}^{-1}$ compared to $325 \mathrm{~W} \mathrm{~m}^{-1} \mathrm{~K}^{-1}$ of diamond/Al composites fabricated by spark plasma sintering [112]. Chen et al. [115] used vacuum hot pressing to fabricate graphite flakes/Al composites with high TC of

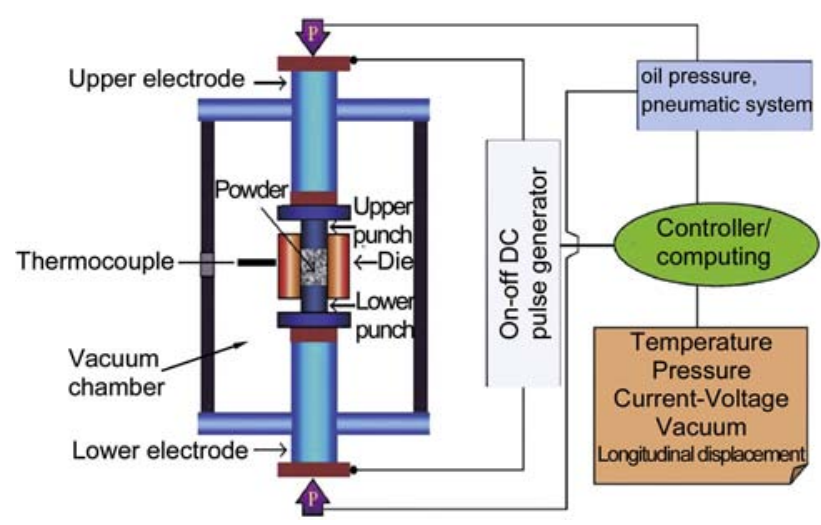

Fig. 9 Schematic diagram of spark plasma sintering [8]
$783 \mathrm{~W} \mathrm{~m}^{-1} \mathrm{~K}^{-1}$. Figure 10 shows the schematic diagram of vacuum hot pressing.

The fabrication method for carbon fibers/Al laminate composites is vacuum hot pressing process, too. However, due to the existence of epoxy, the pressing temperature of this process is much lower than that of the aforementioned vacuum hot pressing process [70]. The stacking sequence design [116], fabrication process [69, 117, 118], fiber/ matrix adhesion $[69,117,118]$, properties $[119,120]$, simulations [121], and applications [70, 122] of these composites have been studied by many researchers.

In summary, both spark plasma sintering and vacuum hot pressing can fabricate $\mathrm{C} / \mathrm{Al}$ composites with good properties. The key point is to find the equilibrium point of interfacial bonding and interfacial reactions, which means that an interface with good bonding but few reactions is needed.

\section{Coatings and Interfaces}

For all kinds of carbon materials, their poor wettability and chemical reactions with aluminum matrixes always retard the improvement of properties [14, 15, 21, 123]. In addition to optimizing the fabrication process aforementioned, a more effective way to solve these problems is to coat the carbon materials. This part will introduce the categories, effects and corresponding interfacial structures of common coatings for carbon materials in aluminum matrix composites.

\subsection{Metallic Coatings}

Metallic coatings are used because they can improve the wetting between carbon materials and aluminum due to the fact that liquid metals can easily wet solid metals [29, 75]. A large variety of metals, such as $\mathrm{Ni}, \mathrm{Cu}, \mathrm{Ag}, \mathrm{Au}, \mathrm{Ti}$ and $\mathrm{W}$, have been tested as coatings for carbon materials.

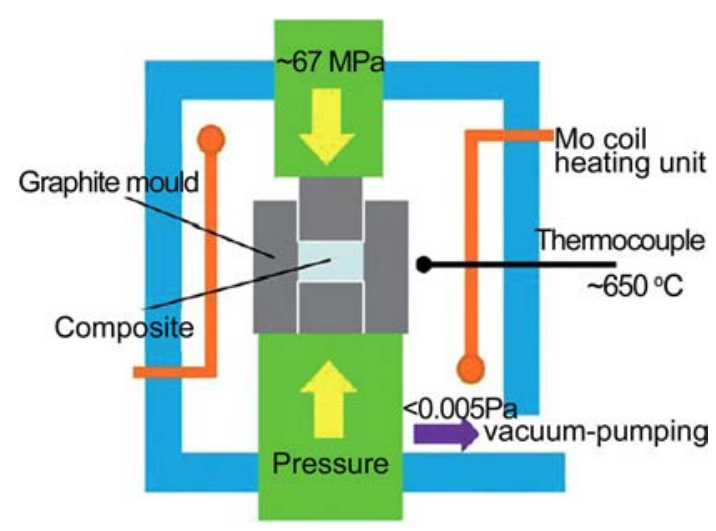

Fig. 10 Schematic diagram of vacuum hot pressing [72] 
The producing methods of metallic coatings include electroless deposition [28, 32, 34, 38, 39], electro-plating [124] and cementation [27]. Coatings produced by cementation have more defects which are detrimental to the properties of the composites [19]. Compared to electroplating, electroless deposition is easier and environment friendly [19, 32, 39], thus, it is a favorite coating method for metallic coatings producing.

Ip et al. [31] studied the wettability of Ni-coated graphite by aluminum, the results show that $\mathrm{Ni}$ can decrease the contact angle from $140^{\circ}$ to only $4^{\circ}$, as shown in Fig. $11 \mathrm{a}, \mathrm{b}$. Rams et al. [32] found that Ni coating can slightly improve the hardness and modulus of carbon fibers/Al composites, while other investigators did not report the properties $[30,33]$. There is no doubt that Ni can improve the wettability of carbon materials by aluminum, but the properties of $\mathrm{Ni}$-coated carbon materials/Al composites are not good due to formation of intermetallic compounds such as $\mathrm{Al}_{3} \mathrm{Ni}$ and $\mathrm{Ni}_{3} \mathrm{Al}_{2}$ (Fig. 11c) [30, 31, 33].

According to the study of $\mathrm{Oh}$ et al. [125], Cu coating can also improve wetting of carbon materials by aluminum through reducing the contact angle from $140^{\circ}$ to $55^{\circ}$ (Fig. 12a, b). Takakazu et al. [28] reported that $\mathrm{Cu}$ coating is better than Ni coating because the bending strength of $\mathrm{Cu}$-coated carbon fibers/Al composites is $491 \mathrm{MPa}$ while that of Ni-coated carbon fibers/Al composites is only $278 \mathrm{MPa}$. Urena et al. [39] successfully used $\mathrm{Cu}$ coating to improve the hardness of short carbon fibers/Al composites. Liu et al. [37] improved the TC of short carbon fibers/Al composites from 117 to $208 \mathrm{~W} \mathrm{~m}^{-1} \mathrm{~K}^{-1}$ by using $\mathrm{Cu}$ coating. Coating processes of $\mathrm{Cu}$ on VGCFs were studied by some researchers [36], and $\mathrm{Cu}$-coated VGCFs were successfully used to improve the mechanical properties of aluminum alloys $[125,126]$. However, in $\mathrm{Cu}$-coated $\mathrm{C} / \mathrm{Al}$ composites, intermetallic compounds such as $\mathrm{CuAl}_{2}$ formed near the interface would reduce the properties of the composites [29, 58], as shown in Fig. 12c.

Metallic coatings such as W [40] and Ti [41, 42] were used in diamond/Al composites to improve interfacial bonding so as to improve TC of the composites. This is due to the fact that $\mathrm{W}$ and $\mathrm{Ti}$ coatings can improve the wettability of diamond and aluminum. For these metallic coatings, carbides such as $\mathrm{WC}$ and $\mathrm{TiC}$ would form at the interface [40-42].

In summary, metallic coatings can improve wetting of carbon materials by aluminum, which has beneficial effects on the interfacial bonding so as to improve thermal properties of the composites. However, the formation of intermetallic compounds or carbides will reduce the mechanical properties of the composites. Thus, metallic coatings are favorable for $\mathrm{C} / \mathrm{Al}$ composites that can be used in thermal management. For structural applications, the formation of the intermetallic compounds or carbides should be controlled by optimizing the thickness of the coatings and the fabrication parameters of the composites.

\subsection{Ceramic Coatings}

Ceramic coatings are used as diffusional barriers so as to retard the harmful interfacial reactions [29, 58]. Ceramic coatings can be divided into carbide coatings and oxide coatings [58]. The common carbide coatings are $\mathrm{SiC}, \mathrm{TiC}$ and pyrolytic carbon, while $\mathrm{Al}_{2} \mathrm{O}_{3}, \mathrm{TiO}_{2}, \mathrm{ZrO}_{2}$ and $\mathrm{SiO}_{2}$ are commonly used as oxide coatings. Due to the high mechanical properties, high dimension stability but relatively low TC of ceramic coatings, they are usually used in structural materials, such as continuous or short carbon fibers/Al composites.
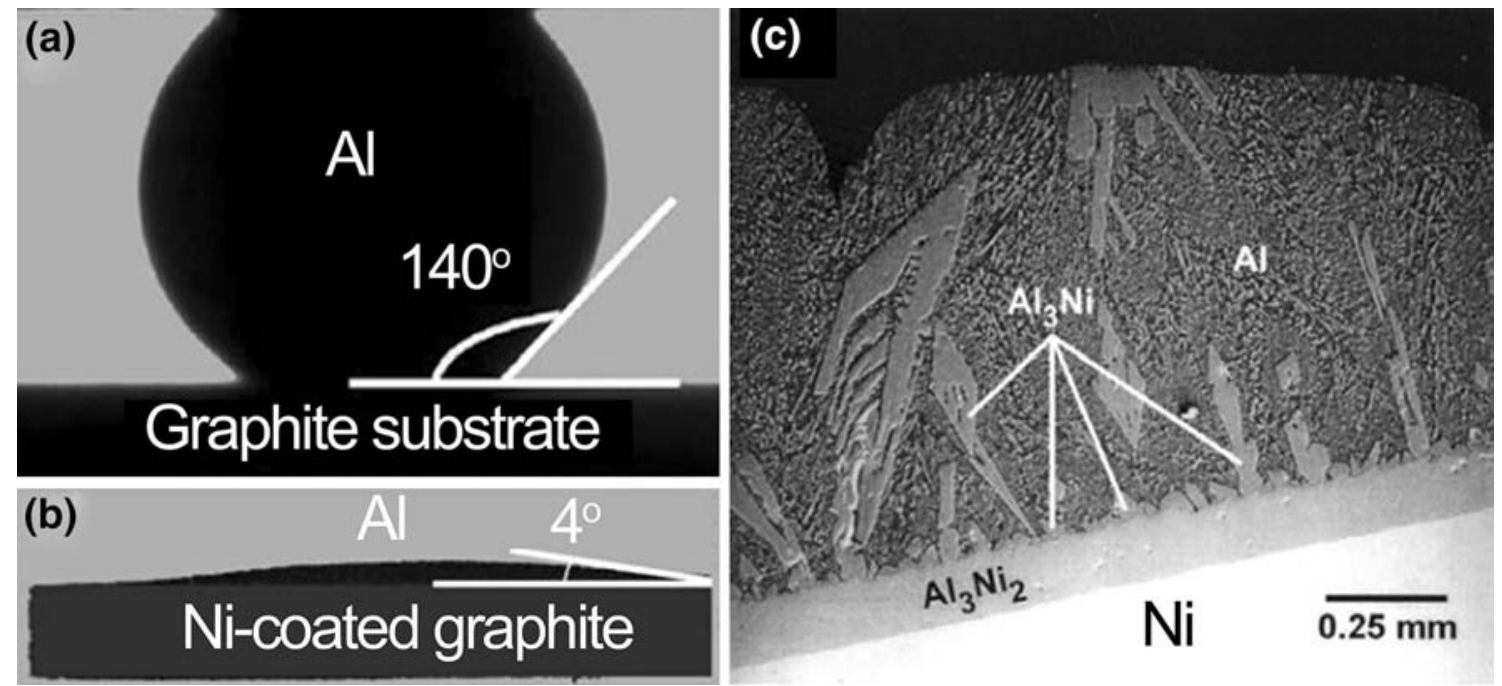

Fig. 11 a, b Wetting improvement of Ni-coated carbon materials by aluminum [31]; c Interfacial microstructure of Ni-coated carbon fibers/Al composites [31] 

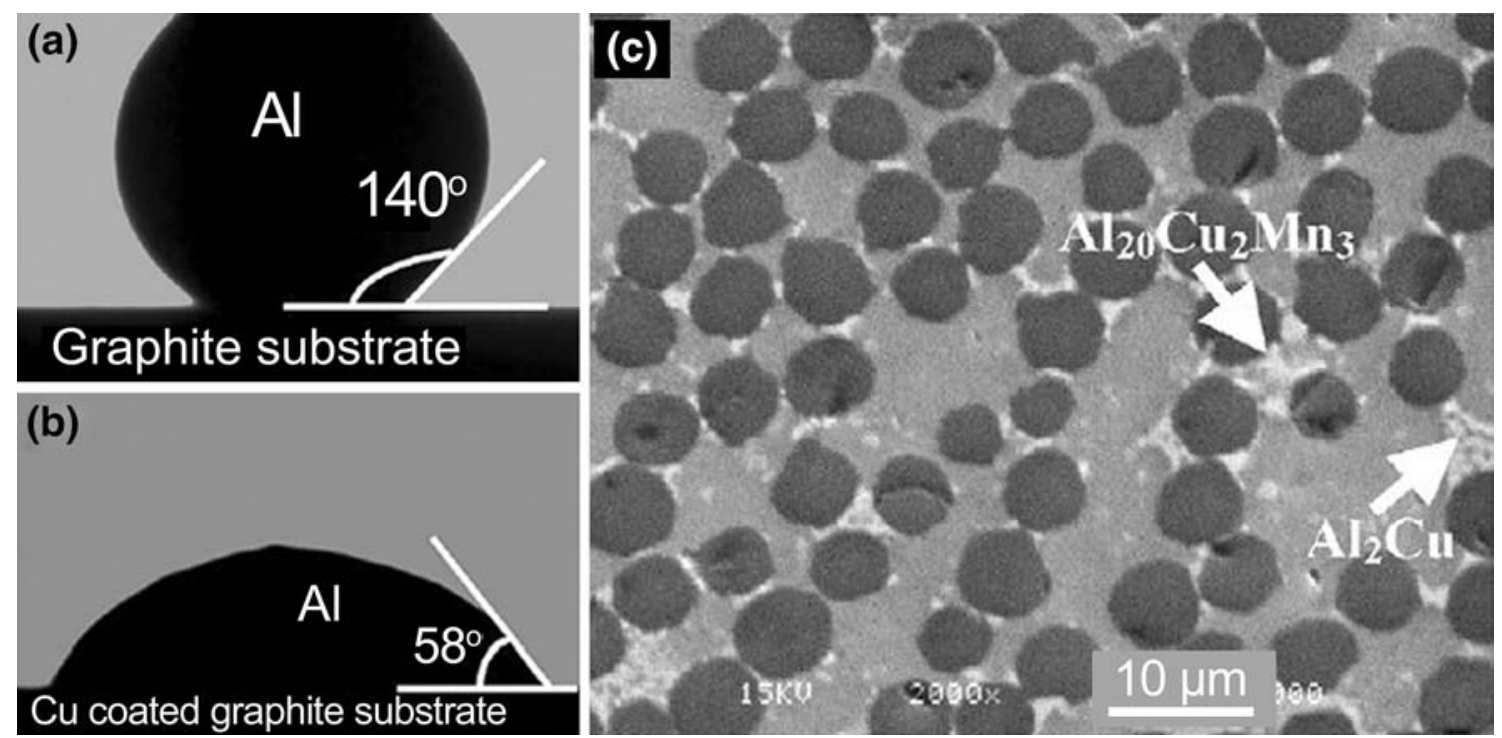

Fig. 12 a, b Wetting improvement of carbon materials by aluminum with $\mathrm{Cu}$ coating [125]; $\mathbf{c}$ Interfacial microstructure of Cu-coated carbon fibers/Al composites [29]

Carbides are of interest because there are by nature the intermediates between carbon and metal, which should be ideal for a carbon/metal interface [58].

$\mathrm{SiC}$ coating has received the most attention probably because $\mathrm{SiC}$ itself is a fine reinforcement for aluminum matrix composites. It is usually applied via a vapor deposition process $[44,127]$ or through pyrolysis of a polycarbosilane polymer $[45,47,48,128]$. In fact, $\mathrm{SiC}$ is less stable than $\mathrm{Al}_{4} \mathrm{C}_{3}$ [58]. Thus, $\mathrm{SiC}$ coating seems to act as a sacrificial coating (as shown in Fig. 13a [127]), which means that the formation of $\mathrm{Al}_{4} \mathrm{C}_{3}$ still exists while the high strength carbon fibers are protected. The degradation of $\mathrm{SiC}$ can be reduced by using an $\mathrm{Al}-\mathrm{Si}$ matrix with high Si content (Fig. 13b [127]). Friler et al. [103] obtained strength of $74 \%$ of rule of mixture by using SiC-coated pitch-based carbon fibers compared to $65 \%$ of rule of mixture by using uncoated fibers. Wang et al. [47] used $\mathrm{SiC}$ coating to improve the strength of carbon fibers/SiC hybrid aluminum composites from 510 to $760 \mathrm{MPa}$.

$\mathrm{TiC}$ coating is studied because it is theoretically more stable than $\mathrm{Al}_{4} \mathrm{C}_{3}$ and would not be degraded by contact with aluminum [46, 58]. Meanwhile, TiC coating can be produced by a liquid metal transfer agent method which is schematically shown in Fig. 14 [46, 49, 51]. This method provided a very attractive alternative to CVD [58]. Himbeault et al. [50] used TiC coating to obtain composites with strength reaching 98\% of rule of mixture, they found that TiC coating is stable during the infiltration of an $\mathrm{Al}-10 \% \mathrm{Mg}$ alloy, however, it is unstable during infiltration with $\mathrm{Al}-12 \% \mathrm{Si}$ alloy due to reaction of the coating with silicon and aluminum.

Pyrolytic carbon is a carbon coating used in carbon fibers/Al composites. It is usually produced by CVD process [44]. Due to its less reactivity with aluminum compared to carbon fibers, it can reduce the formation of $\mathrm{Al}_{4} \mathrm{C}_{3}$ [58]. Hackl et al. [59] reported that pyrolytic carbon coating would strongly accelerate electrochemical corrosion. Ouyang et al. [60] used pyrolytic carbon/SiC hybrid coatings to improve wettability and protect carbon fibers, but the properties of the composites were not reported.

Oxide coatings are chosen due to the function of diffusional barriers and the ease of fabrication through the solgel process $[29,58]$. Sol-gel process is a liquid process
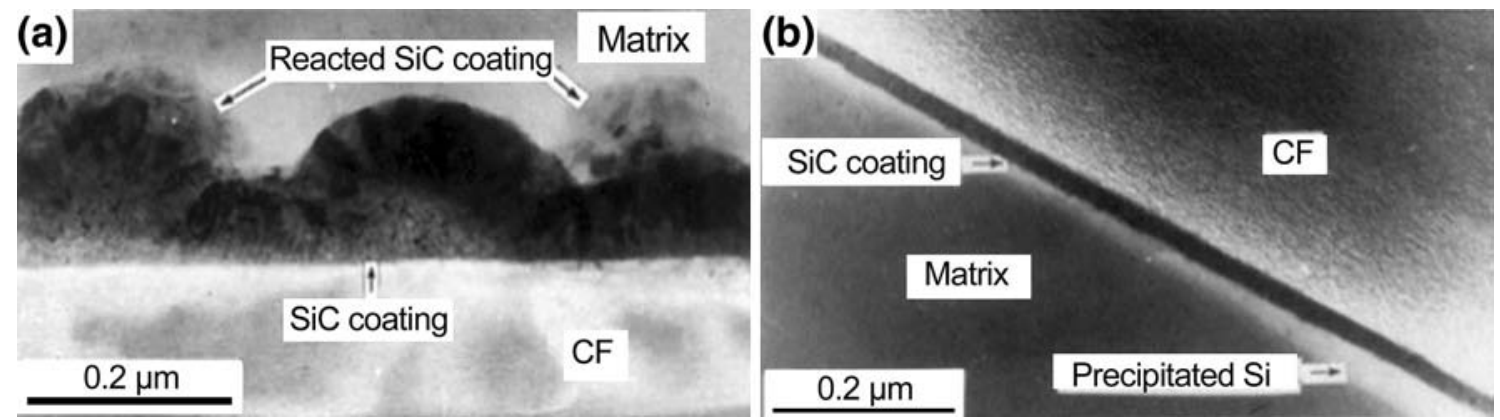

Fig. 13 Interfacial microstructure of SiC-coated carbon fibers/Al composites [127]: a Al-2 wt\% Si matrix; b Al-12 wt\% Si matrix 


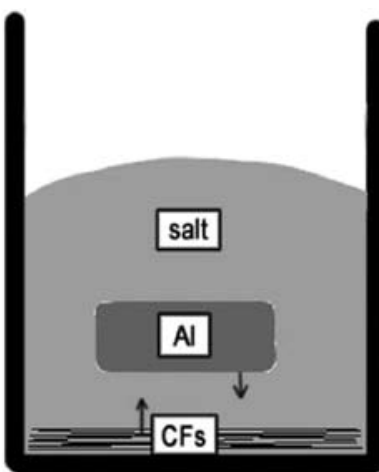

before

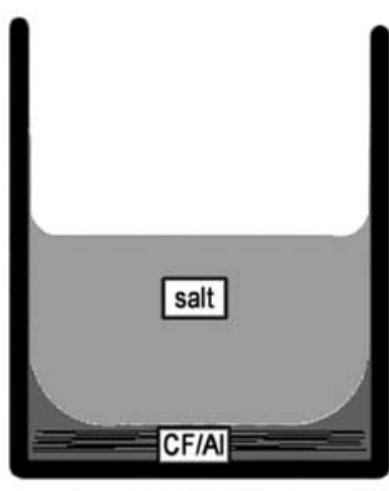

after

Fig. 14 Schematic diagram of liquid metal transfer agent method [51]

which can fabricate oxide coatings in nano-scale. Compared to CVD process, it is easier and more economic.

Zeng [55] fabricated $\mathrm{Al}_{2} \mathrm{O}_{3}$-coated carbon fibers/Al composites wires with strength of $900 \mathrm{MPa}$ compared to $808 \mathrm{MPa}$ of uncoated carbon fibers composites. Peng et al. [129] used $\mathrm{Al}_{2} \mathrm{O}_{3}$ coating to increase the tensile strength of the composites from $559 \mathrm{MPa}$ to only $578 \mathrm{MPa}$; however, strength was increased to $985 \mathrm{MPa}$ by using $\mathrm{Al}_{2} \mathrm{O}_{3}$ /amorphous carbon hybrid coatings. Tang et al. [54] studied the sol-gel process and interfacial structure (Fig. 15) of $\mathrm{Al}_{2} \mathrm{O}_{3}$-coated short carbon fibers/Al composites but no properties were reported.

Other oxide coatings such as $\mathrm{SiO}_{2}$ coating [29], $\mathrm{ZrO}_{2}$ coating [57, 58], and $\mathrm{TiO}_{2}$ coating $[29,56]$ were also studied by some researchers, but few of them reported the properties of the composites.

In summary, ceramic coatings are suitable for structural $\mathrm{C} / \mathrm{Al}$ composite. Both carbide coatings and oxide coatings
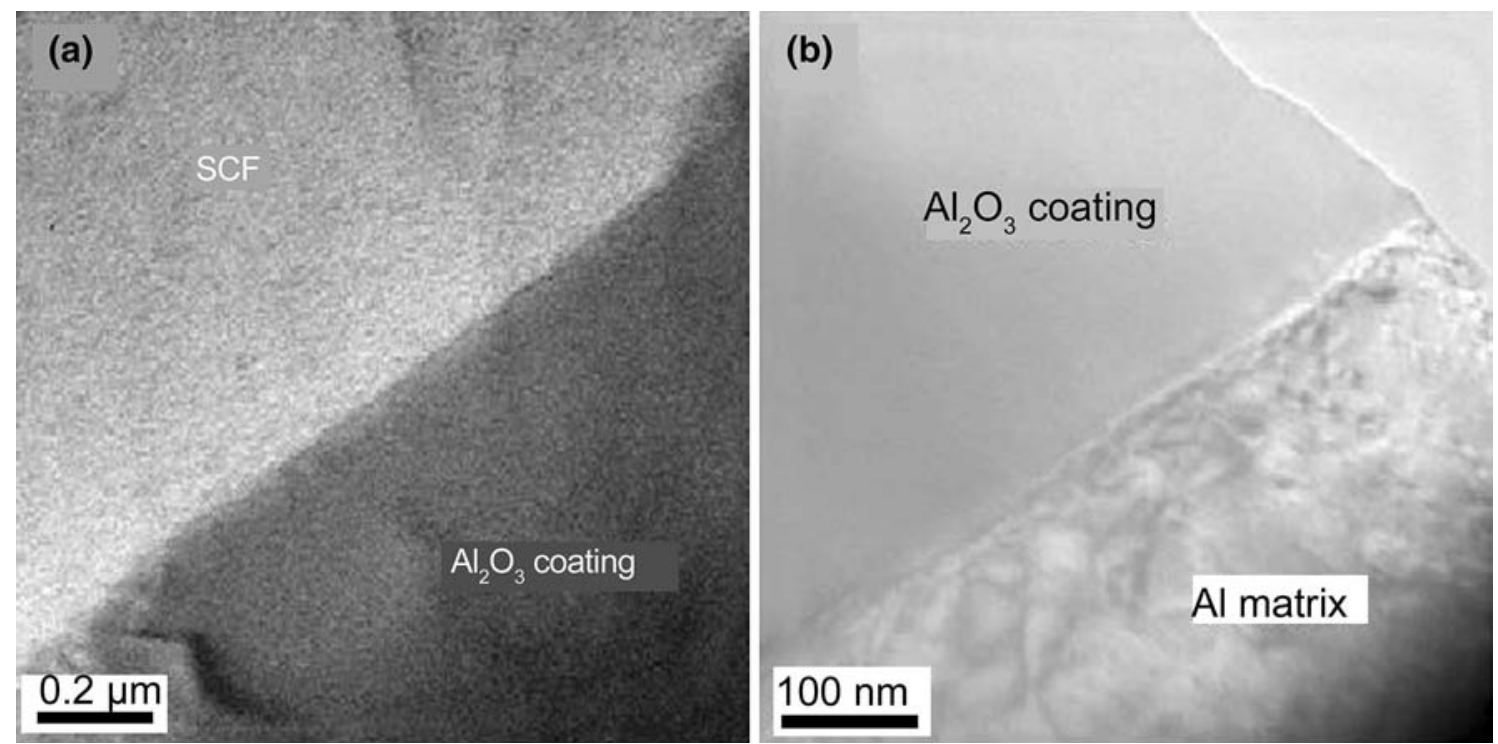

Fig. 15 Interfacial microstructure of $\mathrm{Al}_{2} \mathrm{O}_{3}$-coated short carbon fibers/Al composites [54]: a $\mathrm{Al}_{2} \mathrm{O}_{3}$ coating-carbon fiber interface; b $\mathrm{Al}_{2} \mathrm{O}_{3}$ coating-aluminum matrix interface 
electronic packaging. They possess higher TC and lower density compared to other thermal management materials such as Kavor, $\mathrm{Cu}-\mathrm{W}$ and $\mathrm{SiC} / \mathrm{Al}$. So far, there are already some companies that can produce these composites. Unfortunately, the advantages of these composites have not been taken into full play because of the high interfacial resistance. Thus, how to design the component structure of composites, improve the wettability and control the interfacial structure are important challenges for wider application of these composites in thermal management.

VGCFs, CNTs and graphene are carbon materials possessing the most remarkable mechanical and thermal properties. If the advantages of these reinforcements are fully developed, the corresponding aluminum composites will become the most popular materials that can be used in both structural and functional applications. Unfortunately, the applications of these $\mathrm{C} / \mathrm{Al}$ composites are limited by some technical challenges, such as the high cost and maintenance of same quality, the attainment of homogeneous dispersion, the wetting improvement and the interfacial structure controlling. Thus, more attentions should be paid to the fundamental research of these composites.

Acknowledgments This work was financially supported by National Basic Research Program of China (No. 2012CB619600) and National High Technology Research and Development Program of China (No. 2013AA031201).

\section{References}

[1] D. Chung, Carbon Fiber Composites (Butterworth-Heinemann, London, 1994)

[2] D. Miracle, Compos. Sci. Technol. 65, 2526 (2005)

[3] X.H. Qu, L. Zhang, M. Wu, S.B. Ren, Prog. Nat. Sci. 21, 189 (2011)

[4] M. Inagaki, Y. Kaburagi, Y. Hishiyama, Adv. Eng. Mater. 16, 494 (2014)

[5] S.L. Shindé, J. Goela, High Thermal Conductivity Materials (Springer, Berlin, 2006)

[6] S. Bakshi, D. Lahiri, A. Agarwal, Int. Mater. Rev. 55, 41 (2010)

[7] M. Biercuk, M.C. Llaguno, M. Radosavljevic, J. Hyun, A.T. Johnson, J.E. Fischer, Appl. Phys. Lett. 80, 2767 (2002)

[8] S.C. Tjong, Mater. Sci. Eng. R 74, 281 (2013)

[9] S.V. Kidalov, F.M. Shakhov, Materials 2, 2467 (2009)

[10] C. Zweben, in IEEE International Symposium on Advanced Packaging Materials: Processes, Properties and Interfaces (2001)

[11] Thermal Management Products, (Metal Matrix Cast Composites, 2014), http://www.mmccinc.com/thermal.htm

[12] Aluminum Diamond Thermal Management Material, (Nano Materials International Corporation, 2014), http://www.nanomaterials

[13] K. Landry, S. Kalogeropoulou, N. Eustathopoulos, Mater. Sci. Eng. A 254, 99 (1998)

[14] T. Etter, P. Schulz, M. Weber, J. Metz, M. Wimmler, J.F. Löffler, P.J. Uggowitzer, Mater. Sci. Eng. A 448, 1 (2007)

[15] M. Lancin, C. Marhic, J. Euro. Ceramic Soc. 20, 1493 (2000)

[16] J. Pelleg, D. Ashkenazi, M. Ganor, Mater. Sci. Eng. A 281, 239 (2000)

[17] H.D. Steffens, B. Reznik, V. Kruzhanov, W. Dudzinski, J. Mater. Sci. 32, 5413 (1997)
[18] M. Vidal-Setif, M. Lancin, C. Marhic, R. Valle, J.L. Raviart, J.C. Daux, M. Rabinovitch, Mater. Sci. Eng. A 272, 321 (1999)

[19] C.R. Durkin, Dissertation, Georgia Institute of Technology, 2007

[20] E. Pippel, J. Woltersdorf, M. Doktor, J. Blucher, H. Degischer, J. Mater. Sci. 35, 2279 (2000)

[21] H. Yang, M. Gu, W. Jiang, G. Zhang, J. Mater. Sci. 31, 1903 (1996)

[22] H. Seong, H. Lopez, D. Robertson, P. Rohatgi, Mater. Sci. Eng. A 487, 201 (2008)

[23] H. Ballmes, A. Klassen, C.A. Rottmair, R.F. Singer, Adv. Eng. Mater. 12, 577 (2010)

[24] E. Hajjari, M. Divandari, A.R. Mirhabibi, Mater. Des. 31, 2381 (2010)

[25] Y. Kimura, Y. Mishima, S. Umekawa, T. Suzuki, J. Mater. Sci. 19, 3107 (1984)

[26] B. Pai, G. Ramani, R. Pillai, K. Satyanarayana, J. Mater. Sci. 30, 1903 (1995)

[27] A. Kulkarni, B. Pai, N. Balasubramanian, J. Mater. Sci. 14, 592 (1979)

[28] T. Suzuki, H. Umehara, R. Hayashi, S. Watanabe, J. Mater. Res. 8, 2492 (1993)

[29] T. Rajan, R. Pillai, B. Pai, J. Mater. Sci. 33, 3491 (1998)

[30] S. Abraham, B. Pal, K. Satyanarayana, V. Vaidyan, J. Mater. Sci. 25, 2839 (1990)

[31] S. Ip, R. Sridhar, J. Toguri, T. Stephenson, A. Warner, Mater. Sci. Eng. A 244, 31 (1998)

[32] J. Rams, A. Urena, M. Escalera, M. Sánchez, Compos. A 38, 566 (2007)

[33] Y. Ryu, E. Yoon, M. Rhee, J. Mater. Sci. Lett. 19, 1103 (2000)

[34] Z. Shi, X. Wang, Z. Ding, Appl. Surf. Sci. 140, 106 (1999)

[35] J. Silvain, J. Heintz, M. Lahaye, J. Mater. Sci. 35, 961 (2000)

[36] J. Gomez de Salazar, M. Barrena, C. Merino, N. Merino, Mater. Lett. 62, 494 (2008)

[37] T.T. Liu, X.B. He, Q. Liu, L. Zhang, L. Wang, Q.P. Kang, X.H. Qu, J. Mater. Eng. Perform. 22, 1649 (2013)

[38] B. Bhav Singh, M. Balasubramanian, J. Mater. Process. Technol. 209, 2104 (2009)

[39] A. Ureña, J. Rams, M.D. Escalera, M. Sánchez, Compos. A 38, 1947 (2007)

[40] Z. Tan, Z. Li, G. Fan, Q. Guo, X. Kai, G. Ji, L. Zhang, D. Zhang, Mater. Des. 47, 160 (2013)

[41] X. Liang, C. Jia, K. Chu, H. Chen, J. Nie, W. Gao, J. Compos. Mater. 46, 1127 (2012)

[42] B. Yang, J.K. Yu, C. Chen, Trans. Nonferrous Met. Soc. China 19, 1167 (2009)

[43] N. Sobczak, J. Sobczak, S. Seal, J. Morgiel, Mater. Chem. Phys. 81, 319 (2003)

[44] G. Hackl, H. Gerhard, N. Popovska, Thin Solid Films 513, 217 (2006)

[45] I.H. Kim, W. Lee, C.W. Lee, S.H. Ko, J.M. Jang, Surf. Interf. Analy. 42, 743 (2010)

[46] T. Nieh, A. Vidoz, J. Am. Ceramic Soc. 65, 227 (1982)

[47] J. Wang, T. Hong, G. Li, P. Li, Compos. A 28, 943 (1997)

[48] Y.Q. Wang, B.L. Zhou, J. Mater. Process. Technol. 73, 78 (1998)

[49] P. Baumli, J. Sychev, I. Budai, J. Szabo, G. Kaptay, Compos. A 44, 47 (2013)

[50] D. Himbeault, R. Varin, K. Piekarski, Composites 20, 471 (1989)

[51] K. Juhasz, P. Baumli, G. Kaptay, Materialwissenschaft und Werkstofftechnik 43, 310 (2012)

[52] N. Popovska, H. Gerhard, D. Wurm, S. Poscher, G. Emig, R. Singer, Mater. Des. 18, 239 (1997)

[53] H. Feng, J. Yu, W. Tan, Mater. Chem. Phys. 124, 851 (2010)

[54] Y. Tang, Y. Deng, K. Zhang, L. Liu, Y. Wu, W. Hu, Ceramics Int. 34, 1787 (2008)

[55] Q. Zeng, J. Appl. Polymer Sci. 70, 177 (1998)

[56] J. Clement, H. Rack, K. Wu, H. Spencer, Mater. Manuf. Process. 5, 17 (1990) 
[57] C. Geiculescu, H. Garth Spencer, H.J. Rack, B. Sullivan, Mater. Manuf. Process. 14, 489 (1999)

[58] C. R. Durkin, Dissertation, Georgia Institute of Technology, 2007

[59] B. Wielage, A. Dorner, Compos. Sci. Technol. 59, 1239 (1999)

[60] H. Ouyang, H. Li, L. Qi, Z. Li, T. Fang, J. Wei, J. Mater. Sci. 43, 4618 (2008)

[61] H.O. Pierson, Handbook of Carbon, Graphite, Diamonds and Fullerenes: Processing, Properties and Applications (William Andrew, Norwich, 1994)

[62] S. Chand, J. Mater. Sci. 35, 1303 (2000)

[63] High Thermal Conductive Fiber, (Nippon Graphite Fiber Corporation, 2014), http://www.ngfworld.com/en/en_skill.html

[64] J.M. Ting, M.L. Lake, J. Mater. Res. 10, 247 (1995)

[65] Z.F. Xu, Y.B. Choi, K. Matsugi, D.C. Li, G. Sasaki, Mater. Trans. 50, 2160 (2009)

[66] R. Prieto, J. Molina, J. Narciso, E. Louis, Scr. Mater. 59, 11 (2008)

[67] Y.-K. Kwon, S. Berber, D. Tománek, Phys. Rev. Lett. 92, 015901 (2004)

[68] N.C. Gallego, J.W. Klett, Carbon 41, 1461 (2003)

[69] G. Lawcock, L. Ye, Y. Mai, C. Sun, Compos. Sci. Technol. 57, 1609 (1998)

[70] T. Sinmazçelik, E. Avcu, M.Ö. Bora, O. Çoban, Mater. Des. 32, 3671 (2011)

[71] Z. Tan, Z. Li, G. Fan, X. Kai, G. Ji, L. Zhang, D. Zhang, Diam. Relat. Mater. 31, 1 (2013)

[72] Z. Tan, Z. Li, G. Fan, X. Kai, G. Ji, L. Zhang, D. Zhang, Compos. B 47, 173 (2013)

[73] J. Klett, Compos. Manuf. 14, 1 (1999)

[74] J.L. Song, Y.L. Zhao, X.J. He, D.S. Zhang, Z.C. Tao, Q.G. Guo, X.Q. Gao, J.L. Shi, L. Liu, H.H. Xia, Mater. Sci. Technol. 29, 1389 (2013)

[75] F. Delannay, L. Froyen, A. Deruyttere, J. Mater. Sci. 22, 1 (1987)

[76] H. Naji, S. Zebarjad, S. Sajjadi, Mater. Sci. Eng. A 486, 413 (2008)

[77] V. Michaud, A. Mortensen, Compos. A 32, 981 (2001)

[78] R. Bushby, V. Scott, Compos. Sci. Technol. 57, 119 (1997)

[79] A. Daoud, Mater. Sci. Eng. A 391, 114 (2005)

[80] M. Jacquesson, A. Girard, M.H. Vidal-Sétif, R. Valle, Metall. Mater. Trans. A 35, 3289 (2004)

[81] X. Wang, G. Chen, B. Li, G. Wu, D. Jiang, J. Mater. Sci. 44, 4303 (2009)

[82] Y. Zhang, G. Wu, G. Chen, Z. Xiu, Q. Zhang, C. Wang, Trans. Nonferrous Met. Soc. China 16, 1509 (2006)

[83] W. Hufenbach, M. Gude, A. Czulak, F. Engelmann, Composites 10, 213 (2010)

[84] J. Cai, Y. Chen, V.F. Nesterenko, M.A. Meyers, Mater. Sci. Eng. A 485, 681 (2008)

[85] T. Liu, X. He, Q. Liu, L. Zhang, L. Wang, Q. Kang, X. Qu, J. Mater. Eng. Perform. 22, 1649 (2012)

[86] J.-M. Ting, M.L. Lake, D.R. Duffy, J. Mater. Res. 10, 1478 (1995)

[87] J. Molina, A. Rodriguez-Guerrero, M. Bahraini, L. Weber, J. Narciso, F. Rodriguez-Reinoso, E. Louis, A. Mortensen, Scr. Mater. 56, 991 (2007)

[88] A. Rodriguez-Guerrero, J. Molina, F. Rodriguez-Reinoso, J. Narciso, E. Louis, Mater. Sci. Eng. A 495, 276 (2008)

[89] C.J. Chang, C.H. Chang, J.D. Hwang, C.T. Kuo, in Microsystems, Packaging, Assembly and Circuits Technology Conference, 2009. IMPACT 2009. 4th International IEEE, 2009, p. 461

[90] S. Kleiner, F. Khalid, P. Ruch, S. Meier, O. Beffort, Scr. Mater. 55, 291 (2006)

[91] I. Monje, E. Louis, J. Molina, Composites A 48, 9 (2013)

[92] J.-M. Molina, M. Rhême, J. Carron, L. Weber, Scr. Mater. 58, 393 (2008)
[93] K.K. Chawla, N. Chawla, Metal Matrix Composites (Wiley, Hoboken, 2006)

[94] J.M. Chiou, B.Y. Wei, C.M. Chen, J. Materi, Eng. Perform. 2, 383 (1993)

[95] I.E. Monje, E. Louis, J.M. Molina, Composites A 48, 9 (2013)

[96] T. Shalu, E. Abhilash, M.A. Joseph, J. Mater. Process. Technol. 209, 4809 (2009)

[97] X. Wang, D. Jiang, G. Wu, B. Li, P. Li, Mater. Sci. Eng. A 497, $31(2008)$

[98] M. F. Alam, Disertation, University of Ottawa, 2013

[99] Z. Konopka, M. Łągiewka, M. Nadolski, A. Zyska, Arch. Metall. Mater. 58, 957 (2013)

[100] J. Du, Y.H. Liu, S.R. Yu, W.F. Li, Wear 257, 930 (2004)

[101] Y.H. Liu, J. Du, S.R. Yu, W. Wang, Wear 256, 275 (2004)

[102] B.Q. Li, P.C. Kang, H.S. Gou, Q. Zhang, G.H. Wu, Ceram. Int. 39, 4819 (2013)

[103] J. Friler, A. Argon, J. Cornie, Mater. Sci. Eng. A 162, 143 (1993)

[104] T. Matsunaga, K. Ogata, T. Hatayama, K. Shinozaki, M. Yoshida, Compos. A 38, 771 (2007)

[105] T. Matsunaga, K. Matsuda, T. Hatayama, K. Shinozaki, M. Yoshida, Compos. A 38, 1902 (2007)

[106] Y. Zhou, Y. Xia, Compos. Sci. Technol. 61, 2025 (2001)

[107] G. Sasaki, Z. F. Xu, Y. B. Choi, K. Sugio, K. Mastugi, in Materials Science Forum (Trans Tech Publ, Switzerland, 2012), p. 699

[108] Z.F. Xu, Y.B. Choi, K. Matsugi, D.C. Li, G. Sasaki, Mater. Trans. 51, 510 (2010)

[109] K. Fukuchi, K. Sasaki, K. Katagiri, T.U. Imanishi, A. Kakitsuji, Proc. Eng. 10, 912 (2011)

[110] A. Urena, J. Rams, M. Campo, M. Sanchez, Wear 266, 1128 (2009)

[111] K. Chu, C. Jia, X. Liang, H. Chen, Rare Met. 29, 86 (2010)

[112] K. Chu, C. Jia, X. Liang, H. Chen, W. Gao, Rare Met. 28, 646 (2009)

[113] K. Chu, C.C. Jia, X.B. Liang, H. Chen, Int. J. Min. Metall. Mater. 17, 234 (2010)

[114] K. Mizuuchi, K. Inoue, Y. Agari, Y. Morisada, M. Sugioka, M. Tanaka, T. Takeuchi, J. Tani, M. Kawahara, Y. Makino, Compos. B 42, 825 (2011)

[115] J. Chen, I. Huang, Compos. B 44, 698 (2013)

[116] H.W. Nam, W. Hwang, K.S. Han, J. Compos. Mater. 35, 1654 (2001)

[117] G. Lawcock, L. Ye, Y.W. Mai, C.T. Sun, Compos. Sci. Technol. 57, 35 (1997)

[118] G. Lawcock, L. Ye, Y. Mai, C. Sun, Compos. Sci. Technol. 57, 1621 (1998)

[119] G. Lawcock, L. Ye, Y. Mai, C. Sun, J. Mater. Sci. Lett. 18, 307 (1999)

[120] P. Cortés, W.J. Cantwell, Compos. B 37, 163 (2005)

[121] S. Song, Y. Byun, T. Ku, W. Song, J. Kim, B. Kang, J. Mater. Sci. Technol. 26, 327 (2010)

[122] J. Laliberte, C. Poon, P. Straznicky, A. Fahr, Polymer Compos. 21, 558 (2000)

[123] S.R. Bakshi, A.K. Keshri, V. Singh, S. Seal, A. Agarwal, J. Alloys Compd. 481, 207 (2009)

[124] Y. Tang, L. Liu, W. Hu, J. Mater. Sci. 40, 4399 (2005)

[125] S.I. Oh, J.Y. Lim, Y.C. Kim, J. Yoon, G.H. Kim, J. Lee, Y.M. Sung, J.H. Han, J. Alloys Compd. 542, 111 (2012)

[126] J.Y. Lim, S.I. Oh, Y.C. Kim, K.K. Jee, Y.M. Sung, J.H. Han, Mater. Sci. Eng. A 556, 337 (2012)

[127] X. Chen, G. Zhen, Z. Shen, J. Mater. Sci. 31, 4297 (1996)

[128] Y.Q. Wang, B.L. Zhou, Composites A 27, 1139 (1996)

[129] P. Peng, X.D. Li, G.F. Yuan, W.Q. She, F. Gao, D.M. Yang, Y. Zhuo, J. Liao, S.L. Yang, M.J. Yue, Mater. Lett. 47, 171 (2001) 